\title{
Changes of blood pressure, abdominal visceral fat tissue and gene expressions in fetal programming induced rat model after amlodipine-losartan combination treatment
}

\author{
Ji Hyen Lee ${ }^{1}$, Hyeryon Lee ${ }^{1}$, Sang Mi Lee ${ }^{1}$, Pil Je Kang ${ }^{2}$, Kwan Chang Kim² and Young Mi Hong ${ }^{1 *}$
}

\begin{abstract}
Background: There are a number of complications that can occur if there is under-nutrition during pregnancy followed by a period of rapid catch-up growth, including a higher chance of adult obesity, insulin resistance and hypertriglyceridemia. The purposes of this study were to investigate the effects of fetal under-nutrition during late pregnancy and lactation on blood pressure, visceral fat tissue, gene expressions and to evaluate changes after amlodipine- losartan combination treatment.
\end{abstract}

Methods: The rats were divided into three groups: the control (C) group, the food restriction (FR: $50 \%$ food restricted diet) group, and the CX group, which was treated with Cozaar XQ (amlodipine- losartan combination drug) in FR rats from postnatal 4 to 20 weeks. Masson's trichrome staining was performed in the heart tissues. The amount of abdominal visceral fat tissues was measured. Western blot analysis such as angiotensin converting enzyme (ACE), angiotensin II receptor type IA (ATIA), troponin I (Tn I) and endothelial nitric oxide synthase (eNOS) were performed.

Results: Body weights were significantly higher in the FR group compared with the C group at weeks 8 and 20 and lower in the CX group at week 20. Blood pressure was significantly higher in the FR group compared with the C group at week 20 and lower in the CX group at weeks 12 and 20. The amount of abdominal visceral fat was significantly higher in the FR group compared with the C group at weeks 8, 12 and 20 and significantly lower in the CX group at weeks 16 and 20. Protein expression of ATIA and eNOS were significantly reduced in the CX group at weeks 16 and 20. ACE was significantly reduced in the CX group at week 20 and Tn I was significantly reduced in the CX group at week 16.

Conclusions: When there is fetal under-nutrition during pregnancy, it leads to obesity, high blood pressure, hypertriglyceridemia and several gene changes in offspring. Amlodipine-losartan combination treatment was able to lower obesity, hypertension, hypertriglyceridemia and several gene changes in rats suffering from fetal under-nutrition during pregnancy.

Keywords: Fetal programming, Blood pressure, Visceral fat, Gene expression

\footnotetext{
*Correspondence: hongym@chollian.net

'Department of Pediatrics, Ewha Womans University, 911-1, Mokdong,

YangCheon-Ku, Seoul, South Korea

Full list of author information is available at the end of the article
} 


\section{Background}

Fetal programming, due to maternal under-nutrition, is a critical problem, especially in developing countries. It can lead to the development of metabolic syndrome (MS), hypertension, coronary heart disease and diabetes in adulthood [1]. Early prenatal events in the fetus can result in cardiovascular and metabolic pathologies in both in humans and experimental models [2,3]. Although we know little about the precise mechanisms of fetal programing, some mechanisms have been more extensively studied including glucocorticoid exposure, the role of the kidneys and the renin angiotensin system (RAS) [4, 5]. Other pathophysiological pathways have been investigated, such as the role of the brain and oxidative stress, sympathetic nervous system, and epigenetic changes [4].

Numerous methods have been employed to induce fetal under-nutrition in animal studies such as maternal under-nutrition during pregnancy [6], placental insufficiency [7], or pharmacological manipulations [8].

A reading of the research done in this field mentions a variety of results. We can find evidence in the literature for a link between fetal under-nutrition and an increased risk of MS [3], but other research mentions just components of MS, including hypertension [9], impaired glucose tolerance and insulin resistance [10], dyslipidemia [11, 12], obesity [13] and coronary heart disease [14].

Intrauterine growth retardation may result in a decrease in the expression of genes involved in nephrogenesis [15], as well as a re-directing of nutrients from the kidney to more essential organs such as the brain, heart and adrenal glands in order to increase the survival of the fetus [16]. Sun, et al. reported that offspring exposed to altered maternal nutrition in utero showed modulation of gene expression in adult life associated with subsequent hypertension and dyslipidemia [17].

Blockade of the RAS prevents or gets rid of hypertension in fetal programming animal models, so RAS is most-likely very important in the etiology of prenatal programmed hypertension $[6,18]$. There have been controversies about the effect of antihypertensive drugs such as losartan and angiotensin converting enzyme (ACE) inhibitors on fetal programming models [19]. There have yet to be any reports on the effects of a fixed-dose combination therapy of amlodipine and losartan (Cozaar XQ) in a fetal programming model. Our paper is the first to study about an effect of amlodipine- losartan combination in a fetal programming model.

The purposes of this study were to investigate the effects of fetal under-nutrition during pregnancy and lactation on abdominal visceral fat, lipid profiles, blood pressure and several genes such as ACE, angiotensin II receptor type IA (ATIA), troponin I (Tn I) and endothelial nitric oxide synthase (eNOS) and evaluate changes after amlodipinelosartan combination treatment.

\section{Methods}

Animals

Nine to twelve weeks old virgin female Wistar rats (Sankyo Lab Service, Tokyo, Japan) were maintained at $12 \mathrm{~h}$ light/ $12 \mathrm{~h}$ darkness cycles with free access to tap water and standard rat chow (laboratory animal diet MF; Oriental Yeast, Tokyo, Japan). Female rats were mated with male Wistar rats and conception was confirmed by the observations of semen plugs on the floor of the mating cage.

Pregnant rats were studied from the 10th day to term gestation and through lactation.

Control pregnant rats were fed ad libitum (AdLib) food, whereas the study rats were $50 \%$ food restricted (FR). In this study, only the male offsprings were used. The rats were divided into three groups: the control (C) group $(n=20)$, the food restriction (FR: $50 \%$ food restriction diet $(n=40)$ ] group, CX group $(n=40)$, which was treated with Cozaar XQ (amlodipine- losartan combination drug orally) in the FR rats from postnatal 4 to 20 weeks.

Food intake and maternal weights were recorded daily until birth. After birth, body weight was recorded daily. The rats were sacrificed at weeks 4, 8, 12, 16 and 20. The heart and kidney tissues were removed and immediately frozen at $-70{ }^{\circ} \mathrm{C}$ for protein and gene analysis, post-fixed in $10 \%$ formalin, and processed routinely for paraffin embedding. All protocols were approved by the Institutional Animal Care and Use Committees of the School of Medicine of Ewha Womans University (approval No. 13-0244).

\section{Organ weights}

The rats were weighed and their general appearance was observed daily during the study period. The hearts and kidneys were rapidly removed. The wet weights of the left ventricle (LV) and kidney were measured.

\section{Estimation of abdominal visceral fat tissues}

The amount of abdominal visceral fat (mesenteric, perirenal and pararenal abdominal fat tissues) was estimated at weeks 4, 8, 12, 16 and 20.

\section{Estimation of systemic blood pressure}

The animals were placed in the supine position and instrumented with an arterial pressure line (Physiological Pressure Transducer, MLT 1199; AD Instruments, Oxfordshire, UK). Arterial pressures were estimated at external carotid artery using the input from an ambient-pressure reference (APR-1; Data Sciences) at weeks 4, 8, 12, 16 and 20.

\section{Morphometric analysis of the heart tissues}

The LV including the interventricular septum was weighed after the right and left atria and the right ventricular free wall were dissected. The LV heart tissue was 
fixed in formaldehyde and embedded as a paraffin section in all three groups.

Masson's trichrome staining was used in order to observe the degree of fibrosis in the heart tissues. The area with the most and least degree of fibrosis within each group was selected and photographed under $200 \mathrm{HPF}$ light microscopy. The photographs were processed through an image analysis program (analySIS).

\section{Serum lipid profile}

Blood was drawn from all the rats. They fasted for $12 \mathrm{~h}$ prior to their blood draw to determine blood levels of the following parameters: blood glucose, total cholesterol (TC), high density lipoprotein-cholesterol (HDL-C), low density lipoprotein-cholesterol (LDL-C), triglyceride (TG) at weeks 4, 8, 12, 16 and 20.

\section{Westernblot analysis of heart tissues}

Whole tissue extracts from rat heart were prepared by homogenization in lysis buffer (Proprep, Intron, Seongnam, Korea). Lysates were normalized and separated on 8-12\% polyacrylamide gels and transferred to nitrocellulose blotting membranes (GE Healthcare: formerly Amersham Bioscience, Munich, Germany). After staining with Ponceau red, membranes blocked with $5 \%$ bovine serum albumin an hour at room temperature followed by incubation with primary antibodies including four genes: ACE, ATIA, Tn I, and eNOS (Santacruz Biotechnology, Santa Cruz, CA, USA) overnight.

Nitrocellulose membranes were then washed in t-TBS. The membranes were incubated with horseradish conjugated secondary antibodies for one hour at room temperature. The bound secondary antibody was detected by $\mathrm{ECL}^{\mathrm{T}}{ }^{\mathrm{M}}$ Western blotting detection reagents (GE Healthcare: formerly Amersham Bioscience, Buckinghamshire, UK).

\section{Statistical analysis}

Results are expressed as the mean \pm standard deviation. Data were analyzed using SPSS (SPSS v22.0, Chicago, IL, USA) for windows. The Mann-Whitney test was used to test for significant differences between the $C$ and FR group. The Kruskal-Wallis test was used to test for significant differences between FT group and CX group.

\section{Results}

\section{Body weights}

There was no significant change in body weight at week 4 among the groups.

Body weight was significantly increased at week 8 in the FR group compared with the $\mathrm{C}$ group (C vs. FR; $302.50 \pm$ 16.83 g vs. $369.25 \pm 28.15$ g, $p<0.05$ ), and at week 20 (C vs. FR; $553.50 \pm 13.52$ g vs. $582.10 \pm 19.70$ g, $p<0.05$ ). Body weight was significantly decreased in the CX group compared with the FR group at week 20 (FR vs. CX; $582.10 \pm 19.70$ g vs. $552.30 \pm 1.09$ g, $p<0.05$ ) (Table 1 ).

\section{Abdominal fat tissues}

Abdominal fat tissues were significantly increased in the FR group compared with the $\mathrm{C}$ group at week 8 ( $\mathrm{C}$ vs. FR; $5.26 \pm 0.14$ g vs. $8.38 \pm 0.45$ g, $p<0.05$ ), 12 (C vs. FR; $9.54 \pm 0.59$ g vs. $12.96 \pm 1.01 \mathrm{~g}, p<0.05$ ), and 20 (C vs. FR; $17.77 \pm 2.23$ g vs. $34.83 \pm 10.47$ g, $p<0.05$ ) (Fig. 1 ).

Abdominal fat tissues were significantly reduced in the CX group compared with the FR group at weeks 16 (FR vs. CX; $24.44 \pm 0.93$ g vs. $18.20 \pm 1.55$ g, $p<0.05$ ) and 20 (FR vs. CX; $34.83 \pm 10.47$ g vs.18.36 \pm 3.79 g, $p<0.05$ ), (Fig. 1).

\section{Blood pressure}

Blood pressure was significantly increased in the FR group compared with the $\mathrm{C}$ group at week 20 (119.80 \pm $26.22 \mathrm{mmHg}$ vs. $141.75 \pm 19.70 \mathrm{mmHg})(p<0.05$, Table 2$)$.

Blood pressure was significantly decreased in the CX group compared with the FR group at week 12 (FR vs. CX; $122.00 \pm 9.9 \mathrm{mmHg}$ vs.97.00 $\pm 1.73 \mathrm{mmHg}$ and 20 (FR vs. CX; $141.75 \pm 19.70 \mathrm{mmHg}$ vs. $121.00 \mathrm{mmHg}$ ), $p$ $<0.05$, Table 2).

\section{$\mathrm{LV}+\mathrm{S} / \mathrm{RV}$ ratio}

There was no significant difference among the groups. Data was not shown.

\section{Pathologic finding in heart tissues}

Under light microscopy, collagen was observed to penetrate between the LV myocardiocytes, staining blue as noted in Fig. 2. The degree of collagen was not significantly different in each group.

\section{Westernblot analysis}

Protein expressions of ACE (Fig. 3), AT1A (Fig. 4) and eNOS (Fig. 5) were significantly increased in the FR group compared with the $\mathrm{C}$ group at weeks 16 and 20. Protein expressions of Tn I was significantly increased in the FR group compared with the $\mathrm{C}$ group at week 16 (Fig. 6).

Protein expressions of ACE were significantly decreased in the CX group compared with the FR group at week 20

Table 1 Changes of body weight in fetal programming model after amlodipine-losartan combination treatment

\begin{tabular}{lccr}
\hline Week & $C(\mathrm{~g})$ & FR $(\mathrm{g})$ & \multicolumn{1}{c}{ CX $(\mathrm{g})$} \\
\hline 4 & $90.75 \pm 8.33$ & $85.66 \pm 6.79$ & $97.67 \pm 21.26$ \\
8 & $302.50 \pm 16.83$ & $369.25 \pm 28.15^{*}$ & $333.13 \pm 27.54$ \\
12 & $395.125 \pm 26.575$ & $408.67 \pm 24.95$ & $400.875 \pm 11.89$ \\
16 & $512.38 \pm 20.90$ & $541.50 \pm 35.64$ & $507.50 \pm 15.21$ \\
20 & $553.50 \pm 13.52$ & $582.10 \pm 19.70^{*}$ & $552.30 \pm 1.09 \dagger$
\end{tabular}

$C$ control, $F R$ food restriction, $C X$ amlodipine- losartan combination

${ }^{*} C$ group vs FR group, $p<0.05$, † FR group vs CX group, $p<0.05$ 


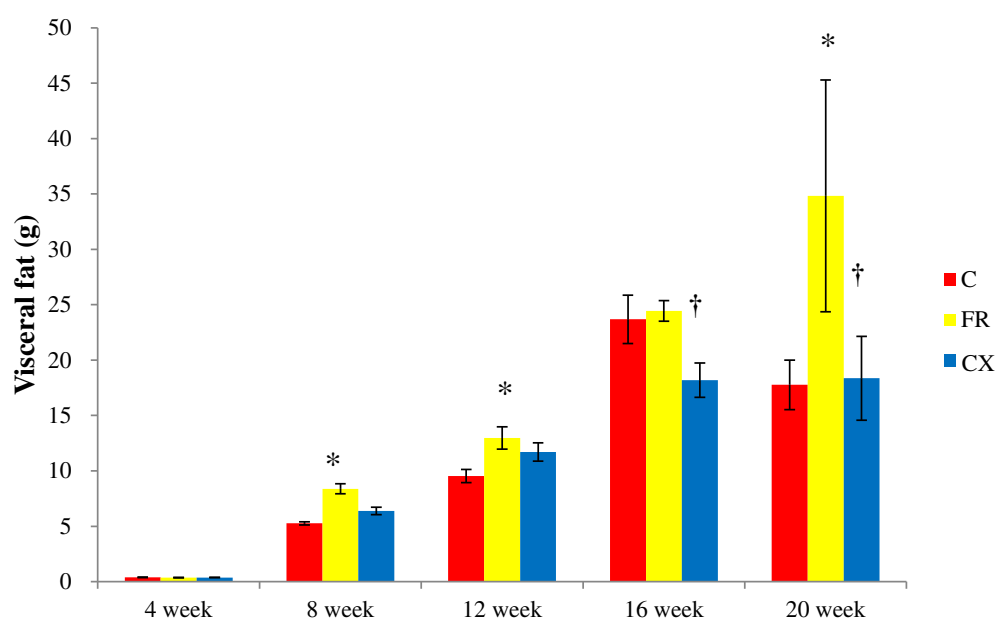

Fig. 1 Abdominal fat tissues in fetal programming model after amlodipine-losartan combination treatment. Abdominal fat tissues were significantly reduced in the CX group compared with the FR group at weeks 16 and 20. C, control; FR, food restriction; CX, Cozaar XQ. ${ }^{*} p<0.05 C$ group vs FR group, $\uparrow p<0.05$ FR group vs CX group

(Fig. 3). Protein expressions of AT1A (Fig. 4) and eNOS (Fig. 5) were significantly decreased in the CX group compared with the FR group at weeks 16 and 20. Protein expressions of Tn I were significantly decreased in the CX group compared with the FR group at week 16 (Fig. 6).

\section{Serum lipid profile}

TG was significantly higher at weeks 8,12 and 20 in the FR group compared with the $C$ group and decreased in the CX group compared with FR group at week 20 $(76.80 \pm 13.03 \mathrm{mg} / \mathrm{dL}$ vs. $42.75 \pm 10.34 \mathrm{mg} / \mathrm{dL}, p<0.05)$.

TC, HDL-C and LDL-C were not significantly different between groups (Table 3 ).

\section{Discussion}

Our research confirmed that fetal under-nutrition during pregnancy resulted in obesity, high blood pressure, hypertriglyceridemia and several gene changes in the offspring.

Body weight was significantly increased at weeks 8 and 20 in the FR group. BP was significantly increased in the FR group at week 20 . Abdominal visceral fat was significantly

Table 2 Changes of blood pressure in fetal programming model after amlodipine-losartan combination treatment

\begin{tabular}{lccc}
\hline Week & $\mathrm{C}(\mathrm{mmHg})$ & $\mathrm{FR}(\mathrm{mmHg})$ & $\mathrm{CX}(\mathrm{mmHg})$ \\
\hline 4 & $86.00 \pm 12.73$ & $82.50 \pm 10.61$ & $84.25 \pm 6.24$ \\
8 & $100.00 \pm 16.57$ & $113.25 \pm 5.32$ & $101.75 \pm 11.76$ \\
12 & $103.25 \pm 6.99$ & $122.00 \pm 9.9$ & $97.00 \pm 1.73 \dagger$ \\
16 & $109.50 \pm 3.32$ & $103.67 \pm 13.58$ & $110.25 \pm 10.24$ \\
20 & $119.80 \pm 26.22$ & $141.75 \pm 19.70^{*}$ & $121.00 \pm 00.00+$ \\
\hline
\end{tabular}

$C$ control, $F R$ food restriction, $C X$ amlodipine-losartan combination

${ }^{*}$ group vs FR group, $p<0.05$, $†$ FR group vs $C X$ group, $p<0.05$ larger at weeks 8, 12 and 20 in the FR group. Protein expressions of ACE, AT1A, eNOS and Tn I were significantly increased in the FR group. TG was significantly higher in the FR group at weeks 8, 12 and 20.

Effects of amlodipine-losartan combination on fetal programming model were as follows.

Body weight was significantly reduced in the CX group compared with the FR group at week 20. Abdominal fat tissues were significantly reduced in the $C X$ group at weeks $8,12,16$ and 20 . BP was significantly decreased in the CX group at weeks 12 and 20. Protein expressions of ACE, AT1A, eNOS and Tn I were significantly decreased in the FR group. TG was significantly decreased in the CX group at week 20.

In our research, amlodipine-losartan combination treatment in fetal programming model reduced obesity, hypertension, hypertriglyceridemia and gene changes.

There has been some controversy related to the results of fetal programing depending on the investigator. We've noticed differences in the literature for the timing of the appearance of elevated BP, as well as its persistence. Most of the research notes elevated BP in animal models between 9 and 12 weeks of age using low protein diet (LPD), reduced uterine perfusion [20] or globally restricted diet [21].

But, the occurrence of the increased BP was different in some research. In the offspring of dams subjected to a $50 \%$ caloric reduction, BP is significantly increased at 4 weeks of age [20]. Vehaskari, et al. reported that after 12 weeks of age, BP either remained unchanged or continued to elevate up to 10 months of age [21]. In a Jansson study, BP appears to diminish as the subject gets older [22]. In our research, BP was significantly increased in the FR group compared with the C group at week 20 . 

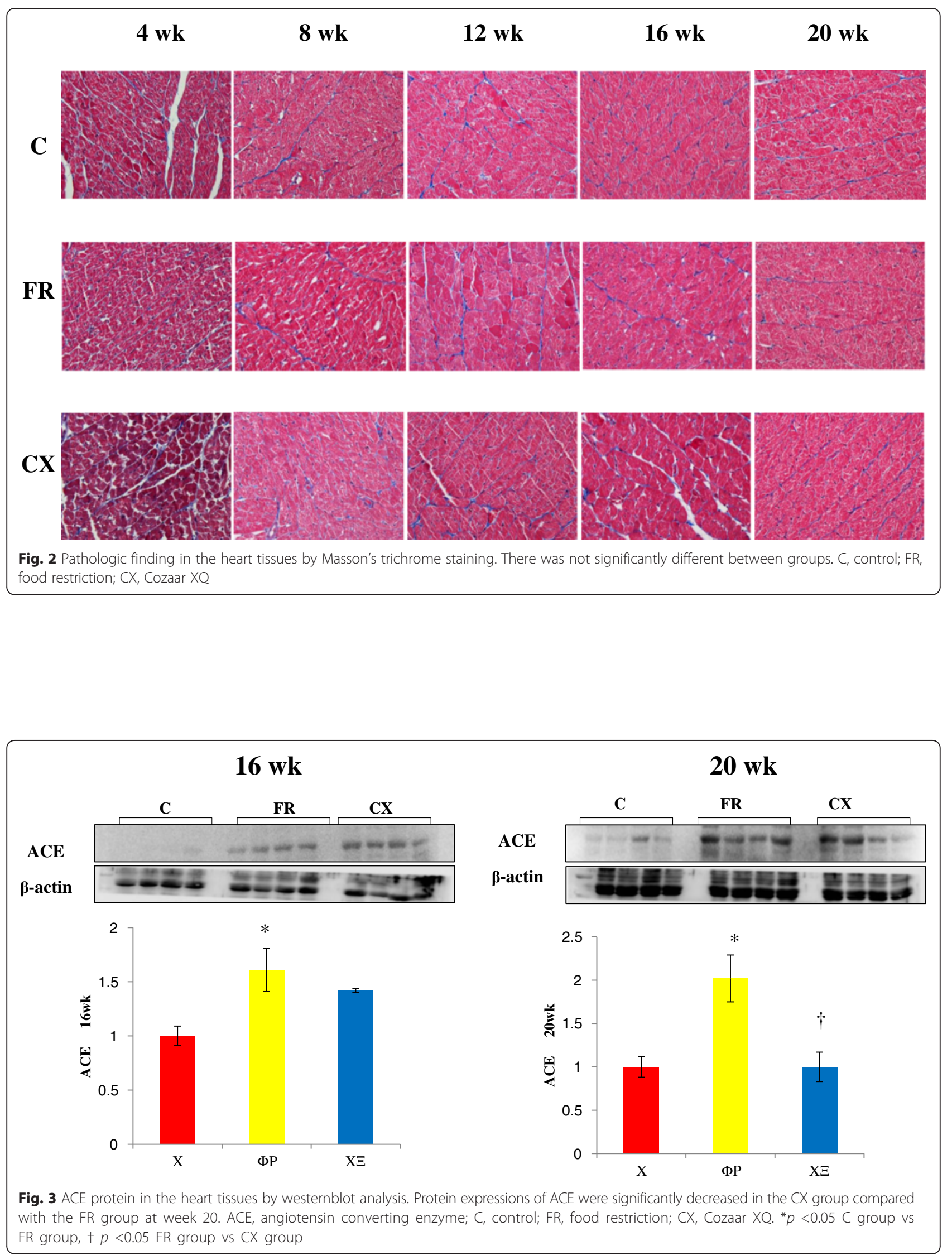




Wintour, et al. noted that there was a difference in BP in fetal programming models, persisting in subjects for up to 7 years of age [8].

The mechanisms of hypertension in fetal programming models are multi-factorial and complex. They include changes of the RAS [23]. Sahajpal, et al. have reported that renal AT1 receptor expressions increased by $24 \%$ in offspring of LPD dams [24]. This suggests that activation of the RAS is one of the most important determinants in hypertension induced by maternal calorie restriction. This finding was similar with our data.

Also, changes of lipid metabolism on fetal programming are different in some investigations [12, 19]. Intrauterine under-nutrition has been linked with an elevated risk of dyslipidemia and insulin resistance, a decrease in insulin content [12] and hyperglycemia in female offspring [25] .

Lucas, et al. noted that dams who were provided with a LPD in both pregnancy and lactation had offspring that at a mean of 6 months had a significant reduction

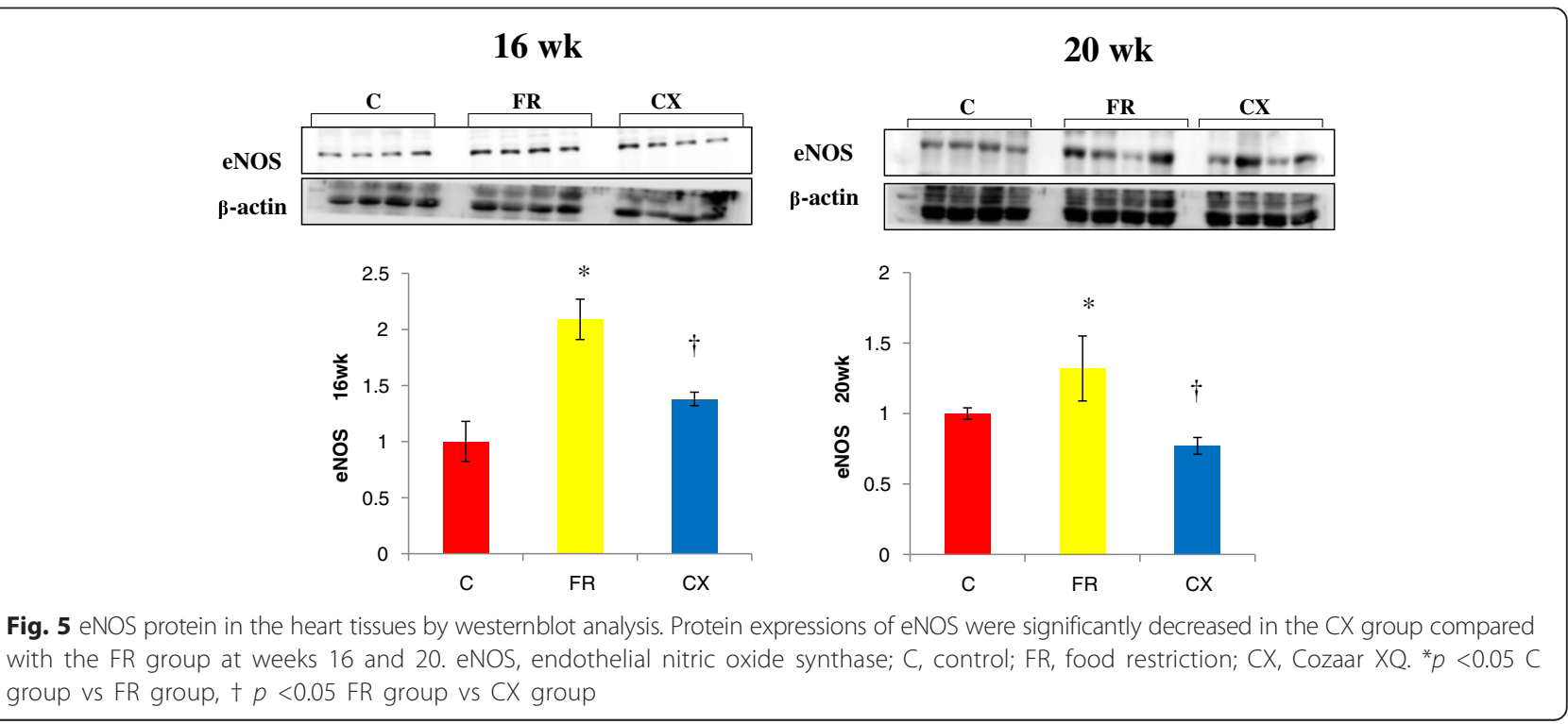



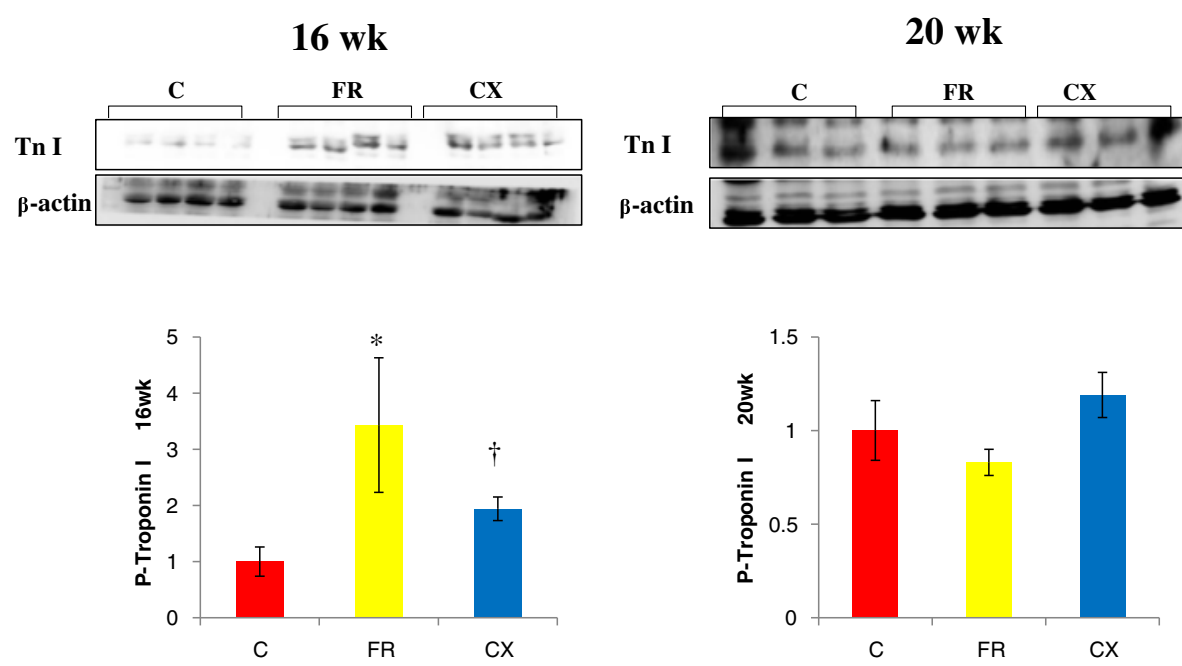

Fig. 6 Troponin I protein in the heart tissues by westernblot analysis. Protein expressions of $T n$ I were significantly decreased in the CX group compared with the FR group at week 16. Tn; troponin; C, control; FR, food restriction; CX, Cozaar XQ. ${ }^{*} p<0.05 C$ group vs FR group, $+p<0.05$ FR group vs CX group

in plasma concentrations of TC, HDL-C and TG compared with the control group [26]. However, Desai, et al. showed that 6-month-old offspring given $50 \%$ food restriction during pregnancy and the lactation period lead to higher TG and normal TC concentrations than the control group [27]. In our research, serum TG was significantly increased in our fetal programming model at weeks 8,12 and 20 .

Mechanism involved in fetal programming may depend on the duration and timing of nutritional insult
[3]. When maternal under-nutrition creates in utero stress, the developing fetus may reprogram the genome to overcome the new, more dangerous environment. This may favor immediate survival but it generally results in a predisposition to metabolic disease in adult life. The development of subsequent chronic disease in adulthood may depend on the amount of difference between pre and postnatal environment [28].

In another study, increased methylation of retinoid $\mathrm{X}$ receptor and eNOS were linked to larger adiposity in

Table 3 Changes of serum lipid profile in fetal programming model after amlodipine-losartan combination treatment

\begin{tabular}{|c|c|c|c|c|c|c|}
\hline Week & & Blood sugar (mg/dL) & $\mathrm{TG}(\mathrm{mg} / \mathrm{dL})$ & $\mathrm{TC}(\mathrm{mg} / \mathrm{dL})$ & $\mathrm{HDL}-\mathrm{C}(\mathrm{mg} / \mathrm{dL})$ & LDL-C (mg/dL) \\
\hline \multirow[t]{3}{*}{4} & C & $288.50 \pm 142.13$ & $107.50 \pm 62.98$ & $84.33 \pm 3.06$ & $65.33 \pm 11.93$ & $18.00 \pm 6.08$ \\
\hline & $\mathrm{FR}$ & $237.00 \pm 108.43$ & $142.00 \pm 47.76$ & $82.67 \pm 2.52$ & $66.67 \pm 0.87$ & $16.00 \pm 4.58$ \\
\hline & $C X$ & $205.00 \pm 0.00$ & $83.00 \pm 2.83$ & $76.50 \pm 2.12$ & $65.50 \pm 0.72$ & $18.00 \pm 0.00$ \\
\hline \multirow[t]{3}{*}{8} & C & $202.00 \pm 14.72$ & $45.75 \pm 14.24$ & $43.00 \pm 6.78$ & $40.50 \pm 6.24$ & $4.50 \pm 1.00$ \\
\hline & $\mathrm{FR}$ & $207.50 \pm 58.34$ & $145.50 \pm 26.80^{*}$ & $62.75 \pm 8.34$ & $56.75 \pm 0.85$ & $7.50 \pm 1.73$ \\
\hline & $C X$ & $263.00 \pm 25.87$ & $105.50 \pm 28.63$ & $62.75 \pm 7.04$ & $57.50 \pm 5.45$ & $9.25 \pm 1.89$ \\
\hline \multirow[t]{3}{*}{12} & C & $127.75 \pm 10.21$ & $20.25 \pm 10.31$ & $42.25 \pm 3.40$ & $42.25 \pm 2.99$ & $5.75 \pm 1.26$ \\
\hline & $\mathrm{FR}$ & $101.00 \pm 18.17$ & $38.25 \pm 7.50^{*}$ & $41.50 \pm 7.59$ & $42.00 \pm 6.68$ & $5.00 \pm 2.16$ \\
\hline & $C X$ & $165.00 \pm 94.69$ & $30.00 \pm 8.54$ & $37.25 \pm 22.51$ & $37.00 \pm 14.72$ & $4.25 \pm 3.86$ \\
\hline \multirow[t]{3}{*}{16} & C & $169.33 \pm 3.33$ & $62.50 \pm 14.50$ & $60.50 \pm 12.82$ & $52.00 \pm 10.39$ & $4.67 \pm 0.47$ \\
\hline & $\mathrm{FR}$ & $189.50 \pm 11.32$ & $81.50 \pm 0.32$ & $54.25 \pm 6.54$ & $48.50 \pm 12.84$ & $5.00 \pm 2.74$ \\
\hline & $C X$ & $191.67 \pm 39.14$ & $86.25 \pm 32.93$ & $54.50 \pm 7.09$ & $445.75 \pm 4.44$ & $5.00 \pm 0.82$ \\
\hline \multirow[t]{3}{*}{20} & C & $141.17 \pm 36.99$ & $33.20 \pm 13.31$ & $48.50 \pm 10.88$ & $45.17 \pm 9.70$ & $5.33 \pm 2.42$ \\
\hline & $F R$ & $195.00 \pm 22.58$ & $76.80 \pm 13.03^{*}$ & $63.71 \pm 17.74$ & $56.71 \pm 16.54$ & $6.17 \pm 3.29$ \\
\hline & $C X$ & $181.00 \pm 19.61$ & $42.75 \pm 10.34 \dagger$ & $68.00 \pm 24.99$ & $63.40 \pm 2.48$ & $8.20 \pm 3.49$ \\
\hline
\end{tabular}

$C$ control, $F R$ food restriction, $C X$ amlodipine losartan-combination, TG triglyceride, TC total cholesterol, HDL-C high density lipoprotein cholesterol, $L D L-C$ low density lipoprotein cholesterol

${ }^{*} \mathrm{C}$ group vs FR group, $p<0.05,+\mathrm{FR}$ group vs CX group, $p<0.05$ 
later childhood which suggests that epigenetics plays a role in fetal programming [29].

Several animal studies have suggested that fetal nutrition acts as epigenetic stimuli to bring about changes in the regulation of gene expression [3]. In our research and some of other research, the epigenetic adaptation persisted from 2 weeks to 4 months of age, which lead to a prediabetic state in the rats [3]. In our research, several gene expressions such as ACE, ATIA, eNOS and Tn I were significantly increased in the FR group.

Glucocorticoid steroids may play a key role in the fetal origins of hypertension, because the increased BP in offspring of LPD dams depends not only on an intact adrenal gland in postnatal life [23], but also on maternal glucocorticoid synthesis during pregnancy [30]. Glucocorticoid steroids may up-regulate the actions of the RAS at the level of angiotensinogen synthesis, ACE, and more importantly, the AT 1 receptor [23, 31].

The effects of antihypertensive drugs on fetal programming model are different according to investigators. Sherman, et al. administrated the ACE inhibitor captopril, for a period of 18 days, beginning at 23 weeks after birth. This gets rid of the hypertension of LPD offspring for some 7-8 weeks after the cessation of treatment [32]. Sherman, et al. have also previously demonstrated that the specific AT1 antagonist losartan at 2-4 weeks of age prevents an increase in BP in offspring of LPD fed dams during pregnancy [32]. We induced the fetal programing model using food restriction during pregnancy and lactation period. We planned losartan treatment at the pilot study from postanatal 4 week to 20 week. There was no response to reduce blood pressure and gene change after losartan treatment postnatally. Therefore, we decided on a postnatally amlodipine-losartan combination in fetal programming models. The amlodipine- losartan combination treatment reduced obesity, hypertension, hypertriglyceridemia and gene changes such as ACE, AT IA, eNOS and Tn I in our study.

In our previous study, we studied changes of gene expressions in a spontaneously hypertensive rat model after losartan treatment. Systolic blood pressure was significantly decreased in the losartan group compared with the hypertension group in weeks 3 and 5. ACE and ATIA proteins in the losartan group were lower than hypertension group in week 5 [33].

Losartan treatment has been reported to significantly reduce body weight in low-protein-exposed rats, but not in animals fed a control maternal diet (18\% casein).

At 12 weeks of age, low-protein-exposed rats treated with losartan at a young age remained normotensive and had body weights similar to those of untreated rats exposed to $9 \%$ casein diets [31]. In our research, amlodipinelosartan combination treatment from week 4 until week 20 decreased BP, body weight and abdominal fat tissues.
Ceravolo, et al. wrote that at 14 weeks of age, losartan (10 $\mathrm{mg} / \mathrm{kg}$, for 15 days) or enalapril treatments stabilized the BP levels and reduced the response to Ang II [19].

Sherman and Langley- Evans [32] found that hypertension does not develop at eight weeks after captopril treatment in a LPD exposed fetal model at postnatal weeks 2-4. This length of treatment could have been sufficient to inhibit the intrarenal angiotensin system, but it was too late in rat renal development to be able to affect nephrogenesis.

Local RAS in the heart, brain and kidney may play a critical role in determining BP.

There are some controversies about the result of ACE activities. Ceravolo, et al. reported no alterations on plasma or tissue ACE activity in intrauterine undernourished rats [19]. However, Langley-Evans SC, et al. have found increased plasma ACE activity in rats exposed to a LPD in utero [34]. These discrepancies observed might be due to differences in the feeding protocol used.

In our study, ACE protein expressions were significantly increased in the FR group and reduced after amlodipinelosartan combination treatment.

Amlodipine-losartan combination have become an exciting therapy for patients with hypertension who have cardiovascular co-morbidities [35]. The advantages of combining amlodipine and losartan include a possible lower incidence rate of side effects such as edema, and increased compliance because of its ease of dosing and its improved tolerability, which may also contribute to greater BP-lowering effects [35] .

The main purpose of fixed-dose combination antihypertensive medications is to significantly improve drug intake, thus improving patient adherence, and, ultimately, to maximize the clinical efficacy and minimize the adverse effects found in monotherapy.

Experimental research suggest that it is the timing of the prenatal insult that is critical to the development of hypertension [6]. Animal studies show that when the prenatal insult occurs during the nephrogenic period, significant increases in mean arterial pressure are noted [6, 36].

Both clinical and experimental evidence suggest that sex may have an important impact on the development of cardiovascular disease that may reflect the regulation of the RAS by gonadal hormones including testosterone and estrogen [2]. Therefore, we performed research in only male offspring to exclude the hormone effect on fetal programming.

Studies into the mechanisms involved in the alterations of endothelium-dependent responses is critical for understanding the pathways by which intrauterine undernutrition leads to endothelium dysfunction and therefore to the development of hypertension and other cardiovascular diseases. Franco, et al. reported that reduced activity of NOS has been described in intrauterine undernourished 
rats [37]. This result is different from our data. In our study, protein expressions of eNOS were significantly increased in the FR group and significantly decreased after amlodipine-losartan combination treatment.

\section{Conclusions}

In conclusion, we established fetal programming model. Fetal under-nutrition only during late pregnancy resulted in obesity, high blood pressure, hypertriglyceridemia and several gene changes in offspring. Amlodipine-losartan combination treatment reduced obesity, hypertension, hypertriglyceridemia and the changes in genes.

\section{Abbreviations \\ C: Control; CX: Cozaar XQ; FR: Food restriction; HDL-C: High density lipoprotein cholesterol; LDL-C: Low density lipoprotein cholesterol; LPD: Low protein diet;} TC: Total cholesterol; TG: Triglyceride.

\section{Competing interests}

The authors declare that they have no competing interests.

\section{Authors' contributions}

$J H L$ participated in the design of the study, performed data collection, statistical analysis, interpreting the data and assisted in drafting the manuscript. $\mathrm{HL}$ and SML carried out animal care and microscopic studies. PJK and KCK performed animal experiments, assisted in interpreting the data and helped in drafting the manuscript. YMH conceived the study, participated in its design, coordinated the research and helped to draft the manuscript. All authors read and approved the final manuscript.

\section{Acknowledgement}

This research was supported by The Society of Korean Hypertension (2014) and Basic Science Research Program through the National Research Foundation of Korea (NRF) funded by the Ministry of Education (2013R1A1A3004619).

\section{Author details}

'Department of Pediatrics, Ewha Womans University, 911-1, Mokdong, YangCheon-Ku, Seoul, South Korea. ${ }^{2}$ Department of Thoracic and Cardiovascular Surgery, Ewha Womans University, Seoul, South Korea.

Received: 15 September 2015 Accepted: 29 January 2016 Published online: 05 April 2016

\section{References}

1. do Carmo Pinho Franco M, Nigro D, Fortes ZB, Tostes RC, Carvalho MH, Lucas SR, et al. Intrauterine undernutrition-renal and vascular origin of hypertension. Cardiovasc Res. 2003:60:228-34.

2. Chappell MC, Marshall AC, Alzayadneh EM, Shaltout HA, Diz DI. Update on the angiotensin converting enzyme 2-angiotensin (1-7)-Mas receptor axis: fetal programing, sex differences, and intracellular pathways. Front Endocrinol. 2014:201:1-13.

3. Lakshmy R. Metabolic syndrome: role of maternal undernutrition and fetal programming. Rev Endocr Metab Disord. 2013;14:229-40.

4. Nuyt AM. Mechanisms underlying developmental programming of elevated blood pressure and vascular dysfunction: evidence from human studies and experimental animal models. Clin Sci (Lond). 2008;114:1-17.

5. Seckl JR. Glucocorticoid programming of the fetus; adult phenotypes and molecular mechanisms. Mol Cell Endocrinol. 2001;185:61-71.

6. Ojeda NB, Grigore D, Hennington BS, Alexander BT. Pre-natal programming of blood pressure and hypertension. Rev Bras Hipertens. 2008;15:3-8.

7. Alexander BT. Placental insufficiency leads to development of hypertension in growth-restricted offspring. Hypertension. 2003;41:457-62.

8. Wintour EM, Moritz KM, Johnson K, Ricardo S, Samuel CS, Dodic M. Reduced nephron number in adult sheep, hypertensive as a result of prenatal glucocorticoid treatment. J Physiol. 2003;549:929-35.

9. Hult M, Tornhammar P, Ueda P, Chima C, Bonamy AK, Ozumba B, et al. Hypertension, diabetes and overweight: looming legacies of the Biafran famine. PLoS One. 2010;5:e13582.
10. Phillips DI, Barker DJ, Hales CN, Hirst S, Osmund C. Thinness at birth and insulin resistance in adult life. Diabetologia. 1994;37:150-4.

11. Lussana F, Painter RC, Ocke MC, Buller HR, Bossuyt PM, Roseboom TJ. Prenatal exposure to the Dutch famine is associated with a preference for fatty foods and a more atherogenic lipid profile. Am J Clin Nutr. 2008:88:1648-52.

12. Lee $\mathrm{S}$, Lee KA, Choi GY, Desai M, Lee SH, Pang MG, et al. Feed restriction during pregnancy/lactation induces programmed changes in lipid, adiponectin and leptin levels with gender differences in rat offspring. J Matern Fetal Neonatal Med. 2013;26:908-14.

13. Kensara OA, Wootton SA, Phillips DI, Patel M, Jackson AA, Elia M. Fetal programming of body composition: relation between birth weight and body composition measured with dual energy X-ray absorptiometry and anthropometric methods in older Englishmen. Am J Clin Nutr. 2005;82:980-7.

14. Lawlor DA, Ronalds G, Clark H, Smith GD, Leon DA. Birth weight is inversely associated with incident coronary heart disease and stroke among individuals born in the 1950s: finding from the Aberdeen children of the 1950s prospective cohort study. Circulation. 2005;112:1414-8.

15. Jones JE, Jurgens JA, Evans SA, Ennis RC, Villar AM, Jose PA. Mechanisms of fetal programming in hypertension. Int J Pediatr. 2012;Article ID584831:1-7.

16. Silver LE, Decamps PJ, Korst LM, Platt LD, Castro L. Intrauterine growth restriction is accompanied by decreased renal volume in the human fetus. Am J Obstet Gynecol. 2003;188:1320-5.

17. Sun C, Burgner DP, Ponsonby AL, Saffery R, Huang RC, Vuillermin PJ, et al. Effects of early-life environment and epigenetics on cardiovascular disease risk in children: highlighting the role of twin studies. Pediatr Res. 2013;73:523-30.

18. Sherman RC, Langley-Evans SC. Antihypertensive treatment in early postnatal life modulates prenatal dietary influences upon blood pressure in the rat. Clin Sci. 2000;98:269-75.

19. Ceravolo GS, Franco MC, Carneiro-Ramos MS, Barreto-Chaves ML, Tostes RC, Nigro D, et al. Enalapril and losartan restored blood pressure and vascular reactivity in intrauterine undernourished rats. Life Sci. 2007;80:782-7.

20. Payne JA, Alexander BT, Khalil RA. Reduced endothelial vascular relaxation ingrowth-restricted offspring of pregnant rats with reduced uterine perfusion. Hypertension. 2003:42:768-74.

21. Vehaskari VM, Aviles DH, Manning J. Prenatal programming of adult hypertension in the rat. Kidney Int. 2001;59:238-45.

22. Jansson T, Lambert GW. Effect of intrauterine growth restriction on blood pressure, glucose tolerance and sympathetic nervous system activity in the rat at 3-4 months of age. J Hypertens. 1999;17:1239-48.

23. Saito T, Musha Y, Miyakawa M, Itoh S, Ohtsuji M, Hanson MA, et al. Angiotensin II receptor antagonist reduces subsequent uterine arterial dysfunction in pregnant offspring of protein-restricted rat dams. J Obstet Gynaecol Res. 2012;38:483-9.

24. Sahajpal V, Ashton N. Renal function and angiotensin AT1 receptor expression in young rats following intrauterine exposure to a maternal low-protein diet. Clin Sci. 2003;104:607-14.

25. Blondeau B, Garafano A, Czernichow P, Bréant B. Age-dependent inability of the endocrine pancreas to adapt to pregnancy: a long-term consequence of perinatal malnutrition in the rat. Endocrinology. 1999;140:4208-13.

26. Lucas A, Baker BA, Desai M, Hales CN. Nutrition in pregnant or lactating rats programs lipid metabolism in the offspring. Br J Nutr. 1996;76:605-12.

27. Desai M, Gayle D, Babu J, Ross MG. The timing of nutrient restriction during rat pregnancy/lactation alters metabolic syndrome phenotype. Am J Obstet Gynecol. 2007;196:555 e1-7.

28. Gluckman PD, Hanson MA. Developmental origins of diseases paradigm: a mechanistic and evolutionary perspective. Pediatr Res. 2004;56:311-7.

29. Godfrey KM, Sheppard A, Gluckman PD, Lillycrop KA, Burdge GC, McLean C, et al. Epigenetic gene promoter methylation at birth is associated with child's later adiposity. Diabetes. 2011;60:1528-34.

30. Langley-Evans SC, Phillips GJ, Jackson AA. Role of glucocorticoids in programming of maternal diet-induced hypertension in the rat. J Nutr Biochem. 1996;7:173-8.

31. Sherman RC, Langley-Evans SC. Antihypertensive treatment in early postnatal life modulates prenatal dietary infuences upon blood pressure in the rat. Clin Sci. 2000;98:269-75.

32. Sherman RC, Langley-Evans SC. Early administration of angiotensin -converting enzyme inhibitor captopril, prevents the development of hypertension programmed by intrauterine exposure to a maternal low-protein diet in the rat. Clin Sci. 1998;94:373-81. 
33. Cha JH, Lee HR, Kim KC, Cho MS, Hong YM. Changes of gene expressions in spontaneously hypertensive rat model after losartan treatment. Korean Circ J. 2012:42:761-8.

34. Langley-Evans SC, Sherman RC, Welham SJM, Nwagwu MO, Gardner DS, et al. Intrauterine programming of hypertension: the role of the reninangiotensin system. Biochem Soc Trans. 1999;27:88-93.

35. Hong BK, Park CG, Kim KS, Yoon MH, Yoon HJ, Yoon JH, et al. Comparison of the efficacy and safety of fixed-dose amlodipine/losartan and losartan in hypertensive patients inadequately controlled with losartan: a randomized, double-blind, multicenter study. Am J Cardiovasc Drugs. 2012;12:189-95.

36. Woods LL, Weeks DA, Rasch R. Programming of adult blood pressure by maternal protein restriction: role of nephrogenesis. Kidney Int. 2004;65:1339-48.

37. Franco MDo C, Arruda RM, Dantas AP, Kawamoto EM, Fortes ZB, Scavone C, et al. Intrauterine undernutrition: expression and activity of the endothelial nitric oxide synthase in male and female adult offspring. Cardiovasc Res. 2002;56:145-53.

Submit your next manuscript to BioMed Central and we will help you at every step:

- We accept pre-submission inquiries

- Our selector tool helps you to find the most relevant journal

- We provide round the clock customer support

- Convenient online submission

- Thorough peer review

- Inclusion in PubMed and all major indexing services

- Maximum visibility for your research

Submit your manuscript at www.biomedcentral.com/submit
Biomed Central 